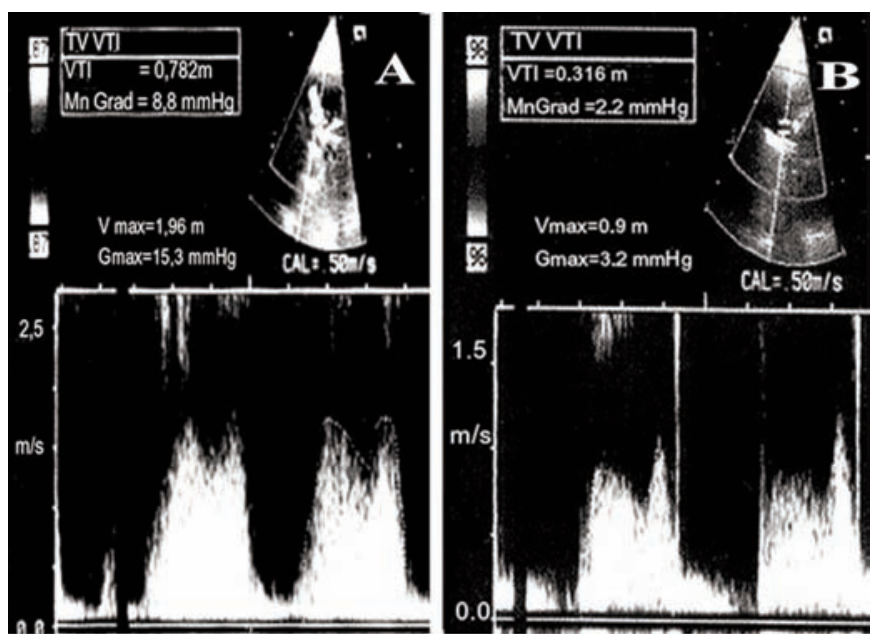

Fig. 1. Doppler continuo del flujo transtricuspídeo. A. Previo al tratamiento gradiente medio $8,8 \mathrm{mmHg}$. $B$. Tras la infusión de rt-PA, con normalización del gradiente medio.

ecocardiografía-Doppler es posible determinar las características hemodinámicas de la prótesis mediante el análisis de los gradientes transvalvulares y el área efectiva valvular. Los valores considerados como normales varían ostensiblemente según el tipo de prótesis, tamaño, posición y la situación hemodinámica del momento, por ello se recomienda la medida de los mismos previos al alta hospitalaria como valores de referencia en cada paciente (5). La ecocardiogafía transesofágica es el método de elección ante la sospecha de TVP, siendo fundamental para la visualización de los discos, así como para evaluar la morfología y posición de los trombos, establecer el diagnóstico diferencial con otros procesos y orientar el tratamiento (5).

Aunque en pacientes con TVP oligosintomáticos puede ser efectivo la intensificación del tratamiento anticoagulante, es la fibrinolisis, con una tasa de éxito del $80 \%$, el tratamiento de elección en las TVP tricuspídeas (2-5). No está establecido el fibrinolítico de elección ni la dosificación a seguir. Aunque existe mayor experiencia con estreptoquinasa y pautas largas (3), parece ser que el tratamiento con rtPA con pauta acelerada, ha sido igual de efectivo, reduciendo también las complicaciones hemorrágicas (4). Además, el control mediante estudio ecocardiográfico seriado, como en nuestro caso, orienta sobre la respuesta al tratamiento fibrinolítico, permitiendo la interrupción del mismo al alcanzar los valores basales de la prótesis (5).

E. Arana Rueda, F. López Pardo, F. Florián Sanz, A. Aguilera Saborido, C. Gómez Navarro, A. Manovel Sánchez

Servicio de Cardiología. Hospital Universitario Virgen del Rocío. Sevilla

1. Azpitarte J, Sánchez-Ramos J, et al. Trombosis valvular prótesica: ¿Cuál es la terapia inicial más apropiada? Rev Esp Cardiol 2001; 54: 1367-76.

2. Thorbun CW, Morgan JJ, Sanahan MX, et al. Long term results of tricuspid valve replacement and the problem of the prosthetic valve thrombosis. Am J Cardiol 1983; 51: 1128-32.

3. Shapira Y, Sagie A, Jortner R, et al. Thrombosis of bileaflet tricuspid valve prosthesis: Clinical spectrum and the role of no surgical treatment. Am Heart J 1999; 137: 721-5.

4. Manteiga R, Souto JC, et al. Short-course thombolysis as the first line of therapy for cardiac valve thrombosis. J Thorac Cardiovasc Surg 1998; 115: 780-4

5. Vasan RS, Kaul U, Sagvis, et al Thrombolytic therapy or prosthetic valve thrombosis: A study based on serial Doppler echocadiographic evaluation. Am Heart J 1992;123 1575-1580.

\section{Meningitis linfocitaria como la única manifestación de una fiebre Q aguda}

\section{Sr. Director:}

La fiebre $\mathrm{Q}$ es una zoonosis de distribución mundial, una enfermedad endémica descrita prácticamente en toda la geografía española (1). Las presentaciones clínicas más frecuentes en la forma aguda y sintomática son la neumonía atípica, hepatitis y síndrome seudogripal. Aunque la cefalea intensa es un síntoma muy frecuente, la meningitis aguda se considera una manifestación rara, estimándose una incidencia en la mayoría de las series inferior al 1\% (2,3). Aportamos un caso de meningitis aguda por fiebre $\mathrm{Q}$ en el que además concurre la excepcionalidad de ser la única manifestación de la enfermedad.

Mujer de 36 años, residente en el medio rural sin exposición directa a animales, con antecedentes de psoriasis en tratamiento tópico, colecistectomia por litiasis biliar y litotricia por nefrolitiasis. Consultó al Servicio de Urgencias por cuadro clínico que se había iniciado unos 5 días antes de su ingreso y consistía en cefalea intensa de predominio occipital, náuseas, vómitos, artromialgias y postración. En la exploración física la paciente se encontraba afectada, consciente, orientada y colaboradora, febril $\left(39^{\circ} \mathrm{C}\right)$ y taquicárdica. Existía rigidez nucal y signos meníngeos. El resto del examen clínico y neurológico fue normal. El fondo de ojo no evidenció papiledema. Las pruebas de laboratorio (hemograma, bioquímica con determinación de enzimas hepáticas, estudio de coagulación) y la radiografía de tórax resultaron normales. La punción lumbar mostró un líquido claro, normotenso, con 470 leucocitos $/ \mathrm{mm}^{3}$ (predominio absoluto de linfocitos), proteínas 58 $\mathrm{mg} / \mathrm{dl}$, glucosa y adenosindesaminasa (ADA) normales. La tinción Gram no evidenció microorganismos. Se estableció el diagnóstico de meningitis aguda linfocitaria, de etiología probablemente vírica, y la paciente recibió tratamiento analgésico parenteral. La evolución inicial fue tórpida por persistencia de la cefalea y la fiebre. Se practicó una tomografía axial computarizada (TAC) cerebral que resultó normal. El cultivo bacteriano, de hongos, la baciloscopia y el cultivo de micobacterias en el LCR fueron negativos. Tampoco crecieron gérmenes en los hemocultivos seriados. Las determinaciones serológicas y de LCR para agentes neurotropos demostraban una IgG sérica frente a Coxiella burnetii en fase II de $1 / 512$ y una IgM de 1/1280, medidas por técnica de inmufluorescencia indirecta (IFI, BioMérieux). No se detectaron títulos de anticuerpos en fase I. La IFI para C. burnetii en LCR resultó negativa. El resto del estudio serológico, incluyendo VIH, fue negativo. A pesar de que la paciente quedó asintomática a las $72 \mathrm{~h}$ de su ingreso, se pautó tratamiento con doxiciclina a dosis de $100 \mathrm{mg} / 12 \mathrm{~h}$ durante 14 días. En seguimientos posteriores no se registraron incidencias clínicas de interés y desde el punto de vista serológico los títulos de IgM habían descendido a la mitad al mes de su ingreso, siendo indetectables a los 4 meses del inicio de los síntomas.

Las manifestaciones neurológicas de la fiebre Q aguda son infrecuentes. En estos casos, la meningitis aguda o la meningoencefalitis es la presentación habitual (4). También se han descrito cuadros neurológicos diversos como cerebelitis, encefalomielitis, síndromes extrapiramidales, psicosis aguda, síndrome de Guillain-Barré, neuritis (óptica, braquial, mononeuritis múltiple) y afectación de pares craneales múltiples $(3,5)$. Los aspectos más destacables de este caso son la aportación de un nuevo episodio de meningitis aséptica como presentación de una fiebre Q aguda y la ausencia de otras manifestaciones clínicas habituales en las formas sintomáticas de la enfermedad, como neumonía y hepatitis. El diagnóstico de la enfermedad aguda se sustenta en el patrón serológico, con títulos elevados de $\operatorname{IgG}$ e $\operatorname{IgM}$ en fase II. 
Solo un $10 \%$ de los pacientes presenta títulos elevados de IgM al inicio de la enfermedad $(5,6)$, como el caso que presentamos. Aunque la PCR puede ser más precoz en la identificación del patógeno, su sensibilidad no es elevada (5). El patrón licuoral, con pleocitosis de predominio linfocitario e hiperproteinorraquia, no se diferencia de las meningitis virales, si bien se han descrito hallazgos de LCR que hacen difícil la distinción inicial con la meningitis tuberculosa (7). El pronóstico, como en la mayoría de las formas clínicas de fiebre Q aguda, es bueno. El tratamiento no difiere de otras formas de fiebre $\mathrm{Q}$ aguda y se basa en la administración de doxiciclina a dosis de $200 \mathrm{mg}$ al día durante 7-14 días (8). En zonas endémicas la fiebre Q debe formar parte del diagnostico diferencial de una meningitis linfocitaria aguda, incluso en ausencia de las manifestaciones clínicas habituales de esta entidad (hepatitis, neumonía).

\section{B. Domínguez-Fuentes, D. García-Gil ${ }^{1}$, F. Brun Romero ${ }^{1}$, J. Benítez Macías ${ }^{1}$}

Servicio de Medicina Interna y ${ }^{\prime}$ Urgencias Hospitalarias. Hospital Universitario Puerto Real. Cádiz.

1. De Alarcón A. Fiebre Q: todavía muchas preguntas por resolver. Enf Infecc Microbiol Clin 2007; 25: 165-7

2. Bernit E, Pouget J, Janbon F, Dutronc H, Martínez P, Brouqui P, et al. Neurological Involvement in Acute Q Fever. Arch Intern Med 2002; 162: 693-700.

3. Raoult D, Tissot-Dupont H, Foucault C, Gouvernet J, Fournier PE, Bernit E, et al. Q Fever 1985-1998: Clinical and Epidemiologic Features of 1,383 Infections. Medicine (Baltimore) 2000; 79: 109-123.

4. Kofteridis DP, Mazokopakis EE, Tselentis Y, Gikas A. Neurological complications of acute Q fever. Eur Epidemiol 2004; 19: 1051-1054.

5. Parker NR, Barralet JH, Morton Bell A. Q fever. Lancet 2006; 367: 67988.

6. Cutler SJ, Bouzid M, Cutler RR. Q fever. J Infection 2007; 54: 313-318.

7. López-Alemany ML, Jordán-Lluch M. Meningitis aséptica por Coxiella burnetii. Enf Infecc Microbiol Clin 1997; 15: 229.

8. Raoult D. Treatment of Q fever. Antimicrob Agents Chemother 1993; 37: 1733-6.

\section{Absceso epidural espinal con espondilitis. Descripción de un caso}

\section{Sr. Director:}

El absceso epidural espinal (AEE) es una colección purulenta localizada en el interior del canal raquídeo entre la duramadre y la columna vertebral adyacente. Es una patología poco frecuente, representa entre uno a dos casos de cada 10.000 ingresos hospitalarios en instituciones terciarias (1-3) y su incidencia está aumentando significativamente. Puede presentarse en cualquier edad con moderado predominio masculino en la sexta década de la vida (4).

Se produce generalmente por siembra hematógena directa del espacio epidural a partir de un foco infeccioso lejano (2). El Staphylococcus aureus es el germen causal más frecuente (60$70 \%$ ) seguido de Streptococcus, gramnegativos y Mycobacterium tuberculosis $(25 \%)$ como señalan diferentes series (2-3,5-7). El primer mecanismo se registra en pacientes con lesiones penetran- tes por extensión (úlceras de decúbito, abscesos paravertebrales, osteomielitis, traumatismos de espalda) y la inoculación e intervención directa al espacio epidural (inyecciones analgésicas, anestesia, cirugía, colocación de catéter y punciones) que ha supuesto un incremento en la incidencia de los abscesos iatrogénicos especialmente en la columna lumbar $(2,4)$. También se registra en procesos infecciosos orofaríngeos, cutáneos, de tejidos blandos, tracto urinario, respiratorio y endocarditis; en pacientes con enfermedades subyacentes predisponentes (diabetes, insuficiencia renal crónica, alcoholismo, VIH) y usuarios de drogas intravenosas. Asienta con mayor frecuencia en la columna dorsal distal (50-80\%) y lumbar (17-38\%), preferentemente en localización posterior $(80 \%)(2,6)$ evidenciando discitis u osteomielitis concomitante en la mayoría de los casos (80\%) (4). La infección epidural puede producir lesión de la médula espinal por compresión mecánica o indirectamente por trombosis del plexo venoso leptomeníngeo. La clínica habitual es dolor vertebral focal, fiebre, seguida de déficit motor y disfunción neurológica. El diagnóstico clínico de sospecha se confirma con resonancia magnética $(\mathrm{RM})$ con gadolinio porque muestra la localización y extensión del absceso, la capacidad multiplanar, la posibilidad de mostrar tejidos blandos y la gran definición de la lesión con sensibilidades próximas al $100 \%(1,6,8)$. El pronóstico depende del cuadro neurológico al ingreso, del diagnóstico precoz y de la instauración de una descompresión quirúrgica temprana mediante laminectomía para preservar la función neurológica $(1,6,8)$, la fijación posterior de la columna para evitar inestabilidad de la misma (9) y, en casos seleccionados, drenaje quirúrgico que permita la tipificación del germen para tratamiento antibiótico $(2,7)$. Presentamos un caso de absceso epidural espinal con espondilitis asociada.

Varón de 68 años con antecedentes de hipertensión arterial, broncopatía crónica, diabetes tipo 2 y consumidor de alcohol de 120 gramos/día. Ocho meses antes presentó un proceso febril con hemocultivos positivos para Staphilococcus aureus betalactamasa positivo. Ingresó por presentar desde dos meses antes y de forma progresiva febrícula de predominio vespertino, dolor dorsolumbar mecánico, parestesias y debilidad en extremidades inferiores, estreñimiento con control esfintéreo, anorexia y adelgazamiento manifiesto. En la exploración física, la palpación de las apófisis espinosas dorsolumbares era dolorosa sin otros hallazgos ni déficits neurológicos. En los análisis practicados destacaba: leucocitos, 12,6 x 10\%/1, neutrófilos, 84\%; hematíes 3,6 x $10^{12} / 1$; hemoglobina, 9,2 g/dl; hematócrito, 29,4\%; plaquetas $550 \times 10 \% / 1$. Glucosa, $170 \mathrm{mg} / \mathrm{dl}$; GGT, $314 \mathrm{U} / \mathrm{l}$. VSG, $120 \mathrm{~mm} / \mathrm{h}$; PCR, > $160 \mathrm{mg} / \mathrm{l}$; fibrinógeno, $420 \mathrm{mg} / \mathrm{dl}$; ferritina, $635 \mathrm{ng} / \mathrm{ml}$; haptoglobina, $360 \mathrm{md} / \mathrm{d}$. Proteínas totales, 7,30 g/dl. Inmunofijación policlonal. La radiografía convencional de la columna dorsolumbar evidenció desestructuración severa discal en T10T11 y L1L2. La RM dorsolumbar puso de manifiesto espondilitis en T10T11 y L1L2 y, en nivel T10T11 masa epidural de predomio posterior con destrucción del disco intervertebral (Fig. 1). Se intervino quirúrgicamente con abordaje posterior, practicándose laminectomía con descompresión medular, osteosíntesis en los pedículos T8T9, L3 y drenaje del absceso. Se aspiró abundante material purulento y se aisló Staphylococcus aureus betalactamasa positivo. El dolor mejoró de manera inmediata. Se trató con cloxacilina intravenosa durante dos semanas, prosiguiéndose por vía oral durante otras seis más. A los tres meses del alta hospitalaria se documentó mediante RM con resolución completa del absceso, así como la normalización de los reactantes.

Consideramos de interés el caso por tratarse de una patología infrecuente $(0,5$ por 10.000 ingresos en nuestro hospital), grave y de no fácil reconocimiento. También por tratarse de un paciente con factores predisponentes y la posible fuente potencial de infección por Staphylococcus aureus con un episodio bacteriémico previo documentado (10). Por la rápida mejoría tras el tratamiento quirúrgico y antibiótico con evolución satisfactoria. Por 